\title{
PEMANFAATAN GULMA BANDOTAN MENJADI PESTISIDA NABATI UNTUK PENGENDALIAN HAMA KUTU KUYA PADA TANAMAN TIMUN
}

\author{
Sultan 1), Patang 2), Subari Yanto2) \\ ${ }^{1}$ Alumni Program Studi Pendidikan Teknologi Pertanian \\ ${ }^{2}$ dan ${ }^{3}$ Dosen PTP FT UNM \\ zhultanz@gmail.com
}

\begin{abstract}
This study aims to know the possibility of Ageratum conyzoides L. used asan organic pesticideand Ageratum conyzoides L. concentration appropriatein controlling pest Aulocaphora sp. Oncucumber plant. This research is experimental research using completely randomised design. There arefour treatment that concentration (3\%), concentration treatment (6\%), concentration treatment (9\%), and control which 3 repetition. Variable research observed behavior and mortality of pest Aulocaphora sp. The results showed Ageratum conyzoides L.extract use has the ability in controlling pest Aulocaphora sp.at concentration 9\%, which can hamper the ability eat and cause silent reaction on pest Aulocaphora sp. furthermore, Aulocaphora sp. that eat the cucumber leaf lowest at concentration $9 \%$.
\end{abstract}

\section{Keywords: Ageratum conyzoides L., organic pesticide, Aulocaphora sp., cucumberplant}

\section{PENDAHULUAN}

Tanaman timun merupakan salah satu jenis tanaman yang menghasilkan buah yang dapat dikonsumsi langsung. Umumnya, timun dapat dijadikan sayuran atau penyegar. Dalam budidaya tanaman timun tidak terlepas dari pemeliharaan tanaman untuk mendapatkan hasil yang baik. Oleh karena itu, budidaya yang optimal seperti penyiraman perlu dilakukan, penyiraman dilakukan minimal dua kali sehari, tetapi apabila hujan turun tanaman tidak perlu dilakukan penyiraman karena tanah sudah cukup air. Selain penyiraman tanaman timun, penyiangan juga perlu dilakukan agar meminimalkan terjadinya persaingan pada tanaman dalam memperoleh unsur hara, sinar matahari, dan sebagainya. Selain itu,tahap pemberantasan hama dan penyakit harus dilakukan. Umumnya, hama yang menyerang tanaman timun adalah hama kutu kuya.

Hama kutu kuya merupakan jenis hama kumbang yang berwarna cerah kuning mengkilap.Siklus hidup hama ini diawali dari perkembangan larvadi dalam tanah. Hama dewasa hidup dibawah daun dan aktif pada siang dan sore hari, apabila terjadi serangan yang cukup tinggi, hama ini memakan daun tanaman timun sampai hanya menyisakan tulangtulang daun. Hama ini mempunyai sifat yang unik yaitu apabila disentuh hama ini akan menjatuhkan dirinya ke tanah seolah-olah hama ini mati, hal ini bertujuan untuk menghindari predatornya. Efek bagi tanaman yang terserang hama ini yaitu dapat menurunkan hasil panen karena daun yang terserang tentunya tidak dapat berfotosintesis dengan baik disebabkan daun pada tanaman timun habis dimakan oleh hama kutu kuya. 
Bahaya residu pestisida bahan
kimia dapat diminimalkan
denganmengembangkan bahan nabat
sebagai bahan pestisida dalam mengendalikan hama kutu kuya. Bahan nabati yang sering digunakan antara lain kedondong, jengkol, kelapa, sirsak, pinang sindawar, jambu biji, lengkuas, lada, bandotan, dan masih banyak lagi bahan nabati lainnya yang dapat dijadikan sebagai pestisida yang ramah lingkungan(Anonim, 2013a). Umumnya, petani masih menggunakan pestisida berbahan kimia yang sangat berbahaya. Residu yang dihasilkan oleh bahan kimia (pestisida) tersebut sangat susah terurai dan membutuhkan waktu yang lama untuk dihilangkan. Pada saat ini, pembasmi hama dan penyakit baik secara organik dan anorganik atau bahan kimia dalam mengendalikan hama pada tanamantelah banyak dikembangkan. Bandotan merupakan gulma pengganggu, di Indonesia bandotan merupakan gulma yang hidup liar dan banyak ditemukan diberbagai daerah. Gulma ini dapat ditemukan di sawah, kebun, pekarangan rumah, dan pinggiran jalan. Meskipun sebagian orang menganggap gulma bandotan sebagai penggangu, ternyata bandotan mempunyai manfaat yang dapat digunakan sebagai pestisida nabati yang ramah lingkungan. Kandungan kimia yang ada dalam tanaman bandotan sangat memungkinkan untuk dijadikan pestisida nabati yang ramah lingkungan (Grainge dan Ahmed dalamAstriani, 2010). Kandungan kimia yang terdapat dalam bandotan adalah saponin, flavonoid, polifenol, eugenol,dan akar bandotan mengandung minyak atsiri,sehingga gulma bandotan dapat dijadikan pestisida yang ramah lingkungan.

\section{METODOLOGI PENELITIAN}

Penelitian ini dilaksanakan padaJuni 2015 sampai Juli 2015. Lokasi penelitian yaitu di perumahan Nusa Tamalanrea Indah dan Perkebunan Warga Patalassang Kabupaten Gowa.

\section{Rancangan Penelitian}

Penelitian ini merupakan penelitian eksperimentaldengan mengaplikasikan ekstrak nabati bandotan dengan konsentrasi $0 \%$ (kontrol), 3\%,6\%, dan $9 \%$ sebagai pestisida nabati.Rancangan acak dilakukan dengan metode undian untuk penentuan tata letak unit percobaan (Tabel 1).

Tabel 1. Tata Letak Unit Percobaan

\begin{tabular}{|c|c|c|c|}
\hline K2 & B3 & A3 & K1 \\
\hline K3 & A2 & B1 & A1 \\
\hline C1 & C2 & C3 & B2 \\
\hline
\end{tabular}

Keterangan :

$\mathrm{K}$ : perlakuan konsentrasi $0 \%$ (kontrol)

A: perlakuan konsentrasi $3 \%$.

B: perlakuankonsentrasi $6 \%$.

C: perlakuankonsentrasi $9 \%$. 


\section{Prosedur Penelitian}

\section{Cara Mendapatkan Hama}

Hama kutu kuya dewasa diperoleh melaluipenangkapan langsung pada lahan petanidengan cara sebagai berikut

a. Jaring penangkap hama kutu kuya yang terbuat dari kain disiapkan agar hama tidak terluka.

b. Toples untuk menampung hama kutu kuya juga disiapkan.

c. Hama yang sudah ditangkap dimasukkan kedalam wadah toples.

\section{Pembuatan Pestisida Nabati Bahan Bandotan}

Prosedur kerja yaitu secara diekstrak (Krestini, 2011)

a. Daun gulma bandotan sebanyak 500 gram yang sudah di cuci bersih menggunakan air disiapkan, kemudian daun gulma bandotan diblender dengan mencampurkan air sebanyak 1 liter air.

b. Larutan ekstrak yang sudah diblender disimpan selama 3 hari agar selama penyimpanan terjadi fermentasi pada ekstrak daun gulma bandotan.

c. Larutan yang sudah di simpan selama 3 hari kemudian disaring agar tidak terdapat kotoran pada ekstrak bandotan.

d. Ekstrak yang sudah jadi dimasukkan ke dalam botol yang bersih agar pestisida yang dihasilkan baik, dan botol yang sudah diisi dengan ekstrak bandotan ditutup kembali agar tidak terjadi kontaminasi. e. Ekstrak bandotan yang telah dikemas disimpan ditempat yang tidak terkena cahaya matahari langsung dan diaplikasikan pada hama yang ingin di kendalikan.

Rumus :

Perhitungan Pembuatan Konsentrasi Ekstrak (Appendi, 2003)

$\mathrm{V}_{1} \times \mathrm{C}_{1}=\mathrm{V}_{2} \times \mathrm{C}_{2}$

Keterangan:

V1 = Volume Larutan yang akan dibuat

(ml)

C1 = Konsentrasi ekstrak yang diambil

$(\mathrm{mg} / \mathrm{ml})$

V2 = Volume larutan ekstrak yang diambil (ml)

$\mathrm{C} 2$ = Konsentrasi larutan yang akan dibuat (mg/ml)

\section{Proses Aplikasi Pestisida Nabati Bandotan}

Proses pengaplikasian ekstrak daun bandotan sebagai pestisida nabati adalah:

a. Daun timun dicelupkan ke dalam larutan ekstrak bandotan sesuai dengan perlakuan selama 15 detik dengan tiga kali ulangan, kemudian ditiriskan dan dikering-anginkan. Setelah kering, daun diberikan pada hama kutu kuya lalu diletakkan ke dalam toples. Selanjutnya, toples yang telah di berikan ventilasi udara ditutup.

b. Jumlah masing-masing hama yang digunakan adalah 10 ekor dalam satu toples dan hama yang di gunakan adalah hama dewasa (imago). Jumlah daun timun yang diberikan pada hama 
sebanyak 10 gram dalam satu toples. Daun yang digunakan adalah daun yang sudah dicelupkan ke dalam ekstrak bandotan.

c. Toples yang berisi daun timun dan hama diberi label berisi keterangan tanggal aplikasi dan jenis konsentrasi perlakuan ekstrak bandotan. Setelah aplikasi, jumlah hama yang mati dihitung pada 72 jam setelah aplikasi ekstrak bandotan.

\section{Parameter Pengamatan}

Parameter yang diamati meliputi pengamatan tingkah laku hama yaitu pada tingkah laku makan, reaksi negatif (bereaksi) dan tingkah laku diam hama yang telah diberikan ekstrak bandotan.

a. Pengamatan Makan. Tingkat makan hama uji yang telah di berikan ekstrak bandotan diamati.

b. Pengamatan Bereaksi. Tingkah laku hama yang sudah memakan daun timun diamati.

\section{Teknik Pengumpulan Data dan Analisis Data}

Teknik pengumpulan data yang dilakukan pada penelitian ini yaitu dengan melakukan metode observasi dengan cara pengamatan dan pencatatan secara sistematik terhadap gejala yang tampak pada subjek penelitian. Pengamatan dan pencatatan secara sistematik pada subjek secara aktif terhadap objek penelitian.Teknik analisis data yang digunakan adalah analisis ragam.

\section{HASIL DAN PEMBAHASAN}

Pada penelitian ini dilakukan pengujian pestisida bandotan dengan mengaplikasikan empat konsentrasi yang berbeda yaitu $0 \%$ (kontrol), 3\%, 6\%, dan $9 \%$ dalam pengujian hama uji kutu kuya, proses penelitian ini mengamati hama uji selama 3 hari dengan sembilan pengamatan dengan interval waktu yang digunakan delapan jam dalam satu hari. Pengamatan tingkah laku hama kutu kuya adalah pengamatan makan, bereaksi, dan diam.

\section{Pengamatan Makan}

Pengamatan pada tingkah laku makan hama dilakukan dengan metode pencatatan secara sistematik terhadap aktivitas makan hama kutu kuya. Pencatatan dilakukan terhadap jumlah hama yangmakan pada saat pengamatan sedang berlangsung, baik pengamatan pagi, siang, dan pengamatan malam hari. Hasil pengamatan menunjukkan perlakuan ekstrak bandotan dengan konsentrasi 9\% menyebabkan jumlah kutu kuya terendah memakan daun timun, yaitu rata-rata $20 \%$. Pada perlakuan ekstrak bandotan dengan konsentrasi $6 \%$ diperoleh hasil rata-rata $34 \%$ sampel, pengamatan ekstrak bandotan dengan konsentrasi 3\% diperoleh hasil dengan rata-rata 39\% sampel. Jumlah kutu kuya yang memakan daun timun tertinggi ditemukanpada perlakuan control, yaitu rata-rata $46 \%$. 
Tabel 2. Rata-Rata Kutu Kuya yang Memakan Daun Timun yang Telah Dicelupkan ke Dalam Larutan Ekstrak Bandotan (Ageratum conyzoides L.)

\begin{tabular}{|c|c|c|c|c|c|c|c|c|c|c|}
\hline \multirow{2}{*}{ Perlakuan } & \multicolumn{9}{|c|}{ Pengamatan (jam) } & \multirow{2}{*}{$\begin{array}{l}\text { Total } \\
\% / 12 \\
\text { sampel }\end{array}$} \\
\hline & 8 & 16 & 24 & 32 & 40 & 48 & 56 & 64 & 72 & \\
\hline $\begin{array}{l}\text { Konsentrasi } \\
3 \%\end{array}$ & $5.67^{a}$ & $5.33^{\mathrm{ab}}$ & $1.00^{a}$ & $6.33^{b}$ & $5.00^{a}$ & $0.33^{a}$ & $6.67^{a}$ & $7.00^{a}$ & $1.00^{a}$ & 39 \\
\hline $\begin{array}{l}\text { Konsentrasi } \\
6 \%\end{array}$ & $5.33^{a}$ & $4.33^{b c}$ & $0.33^{a}$ & $5.00 \mathrm{bc}$ & $4.67 \mathrm{ab}$ & $1.00^{a}$ & $6.00^{a b}$ & $6.33^{a}$ & $0.33^{a}$ & 34 \\
\hline $\begin{array}{l}\text { Konsentrasi } \\
9 \%\end{array}$ & $3.00^{b}$ & $2.33^{c}$ & $0.33^{a}$ & $3.33^{c}$ & $2.33^{b}$ & $0.33^{a}$ & $4.33^{b}$ & $3.67^{b}$ & $0.33^{a}$ & 20 \\
\hline Kontrol & $6.33^{a}$ & $7.00^{\mathrm{a}}$ & $0.00^{\mathrm{a}}$ & $8.33^{a}$ & $7.00^{\mathrm{a}}$ & $0.33^{a}$ & $7.67^{\mathrm{a}}$ & $8.33^{a}$ & $0.33^{a}$ & 46 \\
\hline
\end{tabular}

Keterangan: Nilai rataan yang diikuti oleh huruf yang berbeda dalam kolom yang sama menunjukkan perbedaan yang nyata

Sumber : Data primer setelah diolah, 2015

\section{Pengamatan Bereaksi dan Diam}

Pengamatan pada bereaksi dilakukan juga melalui pencatatan secara sistematik terhadapreaksi yang terjadi pada hama yang telah diberikan ekstrak bandotan serta pengaruh kontak langsung pestisida nabati bandotan yang telah tercerna oleh hama uji kutu kuya. Hasil pengamatan menunjukkan reaksi kutu kuya terendah disekitar daun timun terjadi pada perlakuan kontrol dengan rata-rata $13 \%$ sedangkan hasil pengamatan ekstrak bandotan dengan konsentrasi $3 \%$ diperoleh rata-rata 15\% dan pengamatan ekstrak bandotan dengan konsentrasi $6 \%$ diperoleh hasil dengan rata-rata $17 \%$. Kutu kuya yang bereaksi disekitar daun uji timun tertinggi pada perlakuan ekstrak bandotan dengan konsentrasi $9 \%$ dengan total rata-rata $20 \%$.

Tabel 3. Rata-Rata Hama Kutu kuya yang Bereaksi Disekitar Daun Timun SetelahDicelupkan ke Dalam Larutan Ekstrak Bandotan (Ageratum conyzoides L.)

\begin{tabular}{|c|c|c|c|c|c|c|c|c|c|c|}
\hline \multirow{2}{*}{ Perlakuan } & \multicolumn{9}{|c|}{ Pengamatan (jam) } & \multirow{2}{*}{$\begin{array}{c}\text { Total } \\
\% / 12 \\
\text { sampe }\end{array}$} \\
\hline & 8 & 16 & 24 & 32 & 40 & 48 & 56 & 64 & 72 & \\
\hline $\begin{array}{l}\text { Konsentrasi } \\
3 \%\end{array}$ & $1.67^{a}$ & $1.67^{a}$ & $1.33^{a}$ & $1.33^{a b}$ & $1.67^{a}$ & $2.00^{a}$ & $1.67^{a}$ & $1.67^{a}$ & $1.67^{a}$ & 15 \\
\hline $\begin{array}{l}\text { Konsentrasi } \\
6 \%\end{array}$ & $1.67^{\mathrm{a}}$ & $1.67^{\mathrm{a}}$ & $2.00^{a}$ & $1.67^{a b}$ & $1.67^{\mathrm{a}}$ & $2.00^{a}$ & $2.33^{a}$ & $1.67^{\mathrm{a}}$ & $1.67^{a}$ & 17 \\
\hline $\begin{array}{l}\text { Konsentrasi } \\
9 \%\end{array}$ & $1.33^{a}$ & $2.33^{a}$ & $1.67^{\mathrm{a}}$ & $2.33^{a}$ & $2.00^{a}$ & $2.33^{a}$ & $3.67^{a}$ & $2.33^{a}$ & $2.00^{a}$ & 20 \\
\hline Kontrol & $1.33^{a}$ & $1.00^{a}$ & 3.33a & $0.33^{b}$ & $0.33^{b}$ & $1.67^{a}$ & $1.33^{a}$ & $1.33^{a}$ & $2.33^{a}$ & 13 \\
\hline
\end{tabular}

Keterangan: Nilai rataan yang diikuti oleh huruf yang berbeda dalam kolom yangsama menunjukkan perbedaan yang nyata

Sumber : Data primer setelah diolah, 2015 
Pengamatan reaksi diam dilakukan melalui pencatatan secara sistematik terhadap hama yang memberi respon diamdisekitar daun atau toples setelah bereaksi negatif pada ekstrak bandotan yang di berikan pada hama kutu kuya. Selain itu, pengamatan ini juga dilakukan untuk melihat keefektifan ekstrak bandotan yang digunakan dalam mengendalikan hama kutu kuya. Hasil pengamatan menunjukkan kutu kuya yang memberi respon diam terendah terjadi pada tanpa perlakuan (kontrol) dengan rata-rata $32 \%$ sedangkan hasil pengamatan dengan konsentrasi $3 \%$ diperoleh rata-rata $37 \%$ dan pengamatan ekstrak bandotan dengan konsentrasi $6 \%$ diperoleh hasil dengan rata-rata $40 \%$. Kutu kuya yang memberi respon diam tertinggi dihasilkan oleh perlakuan ekstrak bandotan dengan konsentrasi 9 $\%$ dengan rata-rata $50 \%$.

Tabel 4. Rata-Rata Kutu Kuya yang Diam Disekitar Daun Timun Setelah Dicelupkan ke Dalam Larutan Ekstrak Bandotan (Ageratum conyzoides L.)

\begin{tabular}{|c|c|c|c|c|c|c|c|c|c|c|}
\hline \multirow{2}{*}{ Perlakuan } & \multicolumn{9}{|c|}{ Pengamatan (jam) } & \multirow{2}{*}{$\begin{array}{c}\text { Total } \\
\% / 12 \\
\text { sampel }\end{array}$} \\
\hline & 8 & 16 & 24 & 32 & 40 & 48 & 56 & 64 & 72 & \\
\hline $\begin{array}{l}\text { Konsentrasi } \\
3 \%\end{array}$ & $2.67^{b}$ & $3.00^{b c}$ & $7.67^{a}$ & $2.33^{b c}$ & $3.33^{a b}$ & $7.67^{a}$ & $1.67^{a}$ & $1.33^{b c}$ & $7.33^{a}$ & 37 \\
\hline $\begin{array}{l}\text { Konsentrasi } \\
6 \%\end{array}$ & $3.00^{b}$ & $4.00^{\mathrm{ab}}$ & $7.67^{a}$ & $3.33^{a b}$ & $3.67^{a b}$ & $7.00^{a}$ & $1.67^{a}$ & $2.00^{b}$ & $8.00^{a}$ & 40 \\
\hline $\begin{array}{l}\text { Konsentrasi } \\
9 \%\end{array}$ & $5.67^{a}$ & $5.33^{a}$ & $8.00^{a}$ & $4.33^{a}$ & $5.67^{a}$ & $7.33^{a}$ & $2.00^{a}$ & $4.00^{a}$ & $7.67^{a}$ & 50 \\
\hline Kontrol & $2.33^{b}$ & $2.00^{c}$ & $6.67^{a}$ & $1.33^{c}$ & $2.67^{b}$ & $8.00^{a}$ & $1.00^{a}$ & $0.33^{c}$ & $7.67^{\mathrm{a}}$ & 32 \\
\hline
\end{tabular}

Keterangan: Nilai rataan yang diikuti oleh huruf yang berbeda dalam kolom yang sama menunjukkan perbedaan yang nyata

Sumber : Data primer setelah diolah, 2015

Persentase pengamatan tingkah laku kutu kuya dengan menggunakan konsentrasi $3 \%$ daun timun yang telah dicelupkan kedalam ekstrak bandotan diperoleh total rata-rata makan kutu kuya yaitu sebesar $39 \%$ yang aktif makan.Pada pengamatan bereaksi yang telah dilakukan diperoleh rata-rata bereaksi hama yaitu sebesar $15 \%$ yang aktif bereaksi disekitar daun uji, pada pengamatan tingkah laku diam hama yang telah dilakukan diperoleh rata-rata $37 \%$ yang diam setelah diberikan ekstrak bandotan. Hal ini mungkin dikarenakan ekstrak daun bandotan mempunyai senyawa aktif yang dapat menekan perkembangan makan hama. Senyawa bioaktif dalam bandotan mengandung saponin, flavanoid, polifenol, dan minyak atsiri yang berpengaruh terhadap sistem saraf otot, keseimbangan hormon, reproduksi, perilaku berupa penolak, penarik, anti makan dan sistem pernafasan OPT. Hal ini sesuai dengan pendapat Grainge dan Ahmed dalamDian Astriani (2010), yang menyatakan bahwa bandotan yang dianggap sebagai gulma ternyata mempunyai manfaat sebagai pestisida nabati, karena mengandung saponin, flavanoid, polifenol, dan minyak atsiri. 


\begin{abstract}
Persentase pengamatan tingkah laku hama kutu kuyadengan menggunakan konsentrasi $6 \%$ daun timun yang telah dicelupkan ke dalam ekstrak bandotan diperoleh rata-rata makan kutu kuya yaitu sebesar 34\%yang aktif makan.Pada pengamatan bereaksi yang telah dilakukan diperoleh rata-rata hama yang aktif bereaksi di sekitar daun uji yaitu sebesar 17\%. Pada pengamatan tingkah laku diam,jumlah hama yang memberi respon diam setelah diberikan ekstrak bandotan yaitu rata-rata $40 \%$. Hal ini diduga dalam ekstrak daun bandotan mengandung metabolit sekunder yaitu senyawa saponin, flavanoid, polifenol, dan minyak atsiri. Beberapa senyawa fenol memilki fungsi sebagai penolak hama dan mengurangi adanya reaksi untuk memakan daun timun yang sudah dicelupkan ekstrak bandotan.Pada perlakuan pestisida nabati, ekstrak bandotan memiliki senyawa metabolit sekunder seperti saponin, flavanoid, polifenol dan minyak atsiri (Sianturi, 2009dalamHastuti, 2014). Senyawa bioaktif yang terkandung dalam daun bandotan tersebut berpengaruh terhadap sistem saraf otot hama.
\end{abstract}

Persentase pengamatan tingkah laku kutu kuya perlakuan konsentrasi 9\% ekstrak bandotan diperoleh rata-rata makan kutu kuya yaitu sebesar 20\% yang aktif makan.Pada hasil pengamatan, kutu kuya yang memberi reaksi aktif di sekitar daun timundiperoleh nilai rata-rata yaitu $20 \%$, pada pengamatan tingkah laku diam,kutu kuya yang memberi respon diam setelah diberikan perlakuan ekstrak bandotan $9 \%$ memiliki nilai ratarata $50 \%$. Hal ini disebabkanbandotan memiliki zat metabolit sekunder. Senyawa alkaloid dan terpenoid sangat berpotensi sebagai penghambat makan dan bersifat toksik sehingga menyebabkan hama cenderung diam. Gangguan metabolisme mungkin juga disebabkan karena terdapatnya senyawa tanin dalam makanan yang dapat mengganggu aktivitas enzim pencernaan hama (Dian Astriani, 2010).

Konsentrasi perlakuan esktrak bandotan yang paling efektif diperoleh dari perlakuan konsentrasi 9\%.Pada konsentrasi ini, aktifitas makan hama dapat ditekan dengan nilai rata-rata $20 \%$ dikarenakan bahan aktif pestisida nabati mampu menyebabkan gangguan aktivitas makan dengan mengurangi nafsu makan, memblokir kemampuan makan serangga, sehingga hama menolak makan (Anonim, 2010). Tingkat bereaksi yang ditunjukkanyaitu $20 \%$, makin tinggi tingkat bereaksi hama makin bagus kerja pestisida ekstrak bandotan yang diberikan pada hama kutu kuya. Pada pengamatan tingkat diam, perlakuan ektrak bandotan 9\%menyebabkan peningkatan respon diam pada hama, yaitu rata-rata $50 \%$. Ekstrak bandotan yang diberikan pada hama berfungsi untuk menekan pertumbuhan hama. Senyawa alkaloid dan terpenoid sangat berpotensi sebagai penghambat makan dan bersifat toksik sehingga menyebabkan hama cenderung diam. Gangguan metabolisme mungkin juga disebabkan karena terdapatnya senyawa tanin dalam makanan yang dapat mengganggu aktivitas enzim pencernaan hama (Dian Astriani, 2010). Ini berarti bahwa semakin tinggi konsentrasi ekstrak menyebabkan kondisi tubuh hama semakin lemah dan mengakibatkanpenurunan nafsu makan (Londer dan Shanshen, 1991 dalam Herminanto 2004).

Tanaman bandotan mengandung zat metabolit sekunder yang efektif 
dijadikan pestisida nabati, bersifat ramah lingkungan dimana ekstraknya mengandung senyawa alkoloid seperti saponin, flavonoid, eugeonol, polifenol, minyak atsiri yang dapat menekan aktivitas makan, reaksi negatif, dan diam hama setelah terkontaminasi dengan bandotan melalui makan hama sehingga hama cenderung diam. Zat metabolit yang berperan sangat aktif sehingga bandotan dapat dijadikan sebagai salah satu alternatif pestisida nabati untuk menghambat hama kutu kuya adalah senyawa saponin dan flavonoid. Senyawa ini mampu menekan hama untuk makan dan bereaksi negatif.

\section{Jumlah Daun yang di Makan Hama Kutu Kuya}

Tabel 5. Data Rata-Rata Hasil Timbangan Daun Timun (Cucumis sativu L.) yang Diberikan pada Hama Kutu Kuya (Aulocaphora sp.)

\begin{tabular}{|c|c|c|c|}
\hline Perlakuan & $\begin{array}{c}\text { Timbangan awal } \\
(\text { gram })\end{array}$ & $\begin{array}{c}\text { Timbangan akhir } \\
\text { (gram) }\end{array}$ & $\begin{array}{c}\text { Berat yang dimakan } \\
\text { (gram) }\end{array}$ \\
\hline $3 \%$ & 10 & 5.4 & 4.6 \\
\hline $6 \%$ & 10 & 6.4 & 3.6 \\
\hline $9 \%$ & 10 & 7.1 & 2.9 \\
\hline Kontrol & 10 & 3.0 & 7.0 \\
\hline
\end{tabular}

Sumber : Data primer setelah diolah,2015

Hasil penelitian menunjukkan bahwa perlakuan terbaik diperoleh dari perlakuan konsentrasi 9\% ekstrak daun bandotan. Setelah perlakuan pemberian ekstrak bandotan 9\%diaplikasikan kepada hama kutu kuya,penurunan yang sangat signifikan terjadi, berat awal yaitu 10 gram dan setelah pemberian perlakuan mengalami penurunan berat menjadi rata-rata 2.9 gram. Pada perlakuan konsentrasi $6 \%$, berat timbangan awal 10 gram, setelah dilakukan perlakuan pemberian ekstrak bandotan, berat mengalami penurunan dengan rata-rata menjadi 3.6 gram, sedangkan setelah pemberian perlakuan $3 \%$ ekstrak daun bandotan penurunan menjadi menjadi 4.6 gram.Konsentrasi 9\% merupakan perlakuan terbaik diantara konsentrasi yang diberikan pada hama, karena konsentrasi ini telah mampu menekan kemampuan makan pada hama dan bertindak sebagai penolak hama (Alindatus, 2009). Sifat pestisida ada beberapa, salah satunya adalah sebagai penolak hama untuk merusak tanaman. Pada penelitian ini tidak ditemukan tingkat mortalitas pada hama uji. Hal ini disebabkan oleh beberapa kemungkinan, salah satunya adalah konsentrasi yang digunakan masih rendah. Selain itu, waktu pengamatan relatif singkat sehingga diperlukan pengamatan yang lebih lama yaitu lebih dari 72 jam. Grainge dalam Astriani (2010) bandotan mengandung beberapa senyawa pestisida seperti alkaloid, saponin, flavanoid, polifenol, sulfur dan tanin. Pestisida nabati dapat membunuh atau mengganggu serangga hama melalui cara kerja yang unik yaitu dapat melalui perpaduan berbagai mekanisme atau secara tunggal (Anonim, 2010). Mortalitas yang terjadi mungkin disebabkan oleh perpaduan berbagai mekanisme tersebut. Pada penelitian ini, tidak ditemukan mortalitas pada hama uji. 


\section{KESIMPULAN}

Penggunaan ekstrak bandotan mempunyai kemampuan dalam mengendalikan hama kutu kuya dengan konsentrasi $9 \%$ dapat menekan kemanpuan makan serta reaksi diam pada hama kutu kuya dan hama kutu kuya memakan, reaksi negatif dan diam terendah pada konsentrasi $9 \%$.

\section{DAFTAR PUSTAKA}

Anonim. 2010. Mamfaat Bandotan. 2010/27/manfaat-bandotan-,html. Diakses 10 Semptember 2015.

Anonim. 2013a. Tumbuhan Untuk Bahan Pestisida Nabati. alami.wordpress. go.id/2013/06/29/tumbuhanuntuk-bahan-pestisida-nabati/. Diakses 14 Desember 2013.

Appendi. 2003. repository.usu.ac.id/bitstream/123 456789/29325/1/Appendi.pdf. di akses pada tanggal 22 oktober 2015.

Dewi Hastuti,Abdul Mujib, Mohamad, A. S,. 2014. Uji Efektifitas Larutan Pestisida Nabati Terhadap Hama Ulat Krop (Crocidolomia pavonana L.) Pada Tanaman Kubis (Brassica oleraceae) 1Jurusan Agroekoteknologi, Fakultas Pertanian, Universitas Sultan Ageng Tirtayasa, Jl. Raya Jakarta, KM 04. Pakupatan, Serang, Banten Korespondensi.

Dian Astriani. 2010. pemanfaatan gulma babadotan dan tembelekan dalam pengendalian sitophillus spp. pada benih jagung. Program Studi Agroteknologi
Fakultas Agroindustri Universitas Mercu Buana Yogyakarta.

Krestini. E. H., Wiwin Setiawati., Ineu Sulastrini. 2011. Pengaruh Ekstrak Tumbuhan Babadotan (Ageratum conyzoides),

KIRINYUH(Eupatorium

odoretum),DAN

TAGETES(Tagetes erecta)

Terhadap Mortalitas Hama Myzus

Persicae, Trialeurodes

Vaporariorum, Dan Predator Kumbang Cocci Menochillus sexmaculatus. Balai Penelitian

Tanaman Sayuran, JL.

Tangkuban Parahu 517 Lembang, Bandung.

Herminanto. 2004. Potensi Ekstrak Biji Srikaya (Annona squamosa L.) untuk Mengendalikan Ulat Krop Kubis Crocidolomia Pavonana F. 1) Fakultas Pertanian UNSOED 2) Alumnus Fakultas Pertanian UNSOED.

Nur Alindatus. 2009. Pengaruh Ekstrak Daun Bintaro (Cerbera odollam) terhadap Perkembangan Ulat Grayak (Spodoptera litura F). Jurusan Biologi, Fakultas Matematika dan IImu Pengetahuan Alam, Institut Teknologi Sepuluh Nopember (ITS) JI. Arief Rahman Hakim, Surabaya 60111 Indonesia e-mail: kristanti@bio.its.ac.id UPT Proteksi Tanaman Pangan dan Holtikultura Jawa Timur Jl. Pagesangan II/58, Surabaya 60233 Indonesia. 